\title{
Novel Hybrid Chitosan Derivatives and Chalcones Moiety for Some Biological Applications: Synthesis, Characterization, Antimicrobial and Anti Cancer Activity
}

${ }^{1}$ E. Bagyaraj, E.Vakees ${ }^{2}$ and ${ }^{* 1}$ M. Aboobucker sithique

${ }^{1}$ PG \& Research Department of Chemistry Islamiah College, Vaniyambadi, masithique2@gmail.com, baya.org@gmail.com,admin@islamiahcollege.edu.in

${ }^{2}$ PG \& Research Department of Chemistry, Government Arts College, Tiruvannamalai vakees.e@gmail.com

\section{ABSTRACT}

Versatile hybrid organic polymers are prepared using two active intermediates such as cynuric chloride and chitosan derivatives. The prepared chalcones are characterized by using FTIR, UV, and proton NMR, thermal analysis and Minimum inhibitory Concentration. Thermal stability of the synthesized hybrid polymer is found using TGA and the hybrid chitosan derivative chalcone is thermally stable up to $270^{\circ} \mathrm{C}$. The antimicrobial activity of the prepared chitosan containing chalcone moiety are find out using Minimum Inhibitory Concentration (MIC) method. The synthesized versatile chalcone shows excellent antimicrobial activity against gram-negative bacteria such as Pseudomonas aeruginosa; and Gram-positive bacteria Chalcone containing halogen moiety shows high activity (MIC $7.8 \mu \mathrm{g} / \mathrm{ml}$ ) than the hydroxyl containing chalcone. Cytotoxicity activity of the synthesized composites shows high activity.

KEYWORDS: Chitosan; Aldehydes; Chalcone; MIC; Anti-cancer activity.

* Corresponding Author, Tel: +919488213387, E-mail address: masithique2@ gmail.com 


\section{INTRODUCTION}

Chitosan is a cationic natural biopolymer produced by alkaline $\mathrm{N}$-deacetylation of chitin (1-2). It has good biocompatibility, as well as extensive applications in pharmacology, biomedicine, agriculture, food and waste treatment (3). Because to infer its porous structure should have a higher adsorption capability and further applications such as drug delivery and anti-cancer. Studies on chemical modification of chitosan have been extensively performed to introduce novel functions (4). Recently, we have succeeded in the synthesis of chitosan containing chalcone moiety. Chemical modification of the N-substituted and O-substituted Chitosan follows the homogeneous phase reaction. Chitosan has shown to possess high antibacterial activity, toxicity, high killing rate and low for mammalian cells (5). Many mechanisms have been reported to justify the antibacterial activity of Chitosan at gram negative bacteria and gram positive bacteria can be referred in the term of its chemical and structural properties (6). The antimicrobial properties for water soluble chitosan were screened by the minimum inhibitory concentration (MIC) using different concentrations for two bacterial strains. Chitosan is known to be nontoxic and biocompatible, material. The chalcones along with its biocompotitable novel hybrid chitosan materials as expected, to possess better anticancer and antibacterial drug properties. The introduction of bio polymer chitosan in to the other biologically active chalcones moiety would replace bio based polymer and thereby helps in sustainable growth in the field.

\section{EXPERIMENTAL METHODS}

\subsection{Materials}


Chitosan (98\%deacetylation) was purchased from R\&M Marketing supplied U.K 99\% Glacial acetic acid were purchased from SIGMA-ALDRICH. 2, 4-dichloroacetophenone and 4aminoacetophenone were purchased from Merck and used as such. 4-hydroxybenzaldehyde, Benzaldehyde, 4-nitrobenzaldehyde, 4-bromobenzaldehyde, 4-chlorobenzaldehyde, para N,N dimethylbenzaldehyde, 4-aminobenzaldehyde and Cyanuric chloride were purchased from Aldrich chemical and used as such. All the solvents were purchased from S.D. Fine chemicals and used as such.

\subsection{Synthesis of 4-((2s,3s,4r,5r,6s)-3-amino-2,5-dimethoxy-6-((4-oxocyclohexa-2,5-dien-1- yl)oxy)methyl)tetrahydro-2h-pyran-4-yl)oxy)cyclohexa-2,5-dienone (AMC).}

The chitosan containing Para benzoquinone was prepared in three steps, namely; Chitosan activation, animation and distillation. In the first step, chitosan activation, $4 \mathrm{gm}$ of chitosan was dispersed in $50 \mathrm{ml}$ of distilled water at defined $\mathrm{pH}$, dissolved in it $\mathrm{pBQ}$ and stirred for $6 \mathrm{hr}$. The activated chitosan (ATC) was separated and washed well with distilled water. The second step is chitosan animation, ATC was taken in $50 \mathrm{ml}$ of distilled water dissolved using ethylene diamine and stirred for $6 \mathrm{hr}$, and after the completion of the reaction the obtained product aminated modified chitosan (AMich) was separated and washed well with distilled water. The last step is the chitosan deacetylation, performed according to Rigby and Wolfarn method $(9,10)$. The aminated chitosan derivative was treated with $40 \%$ aqueous solution of $\mathrm{NaOH}$ at $120-150{ }^{\circ} \mathrm{C}$ for $6 \mathrm{hr}$. The obtained aminated chitosan (AMC) was separated and washed well with distilled water. The FT-IR spectrum of the (AC) conform the formation of the compound the broad peak appeared at $3430 \mathrm{~cm}^{-1}$ is due to the presence of hydroxyl group of chitosan, and the NH stretching frequency absorbed at $2540 \mathrm{~cm}^{-1} \cdot$ the aromatic $\mathrm{C}=\mathrm{C}$ stretching 
frequency appeared at $2995 \mathrm{~cm}^{-1}$, and stretching frequency of oxygen connected with carbon of benzoquinone is appeared at $1637 \mathrm{~cm}^{-1}$

\subsection{Synthesis of modified chitosan containing acetophenone (Scheme 2)(CYDHP)}

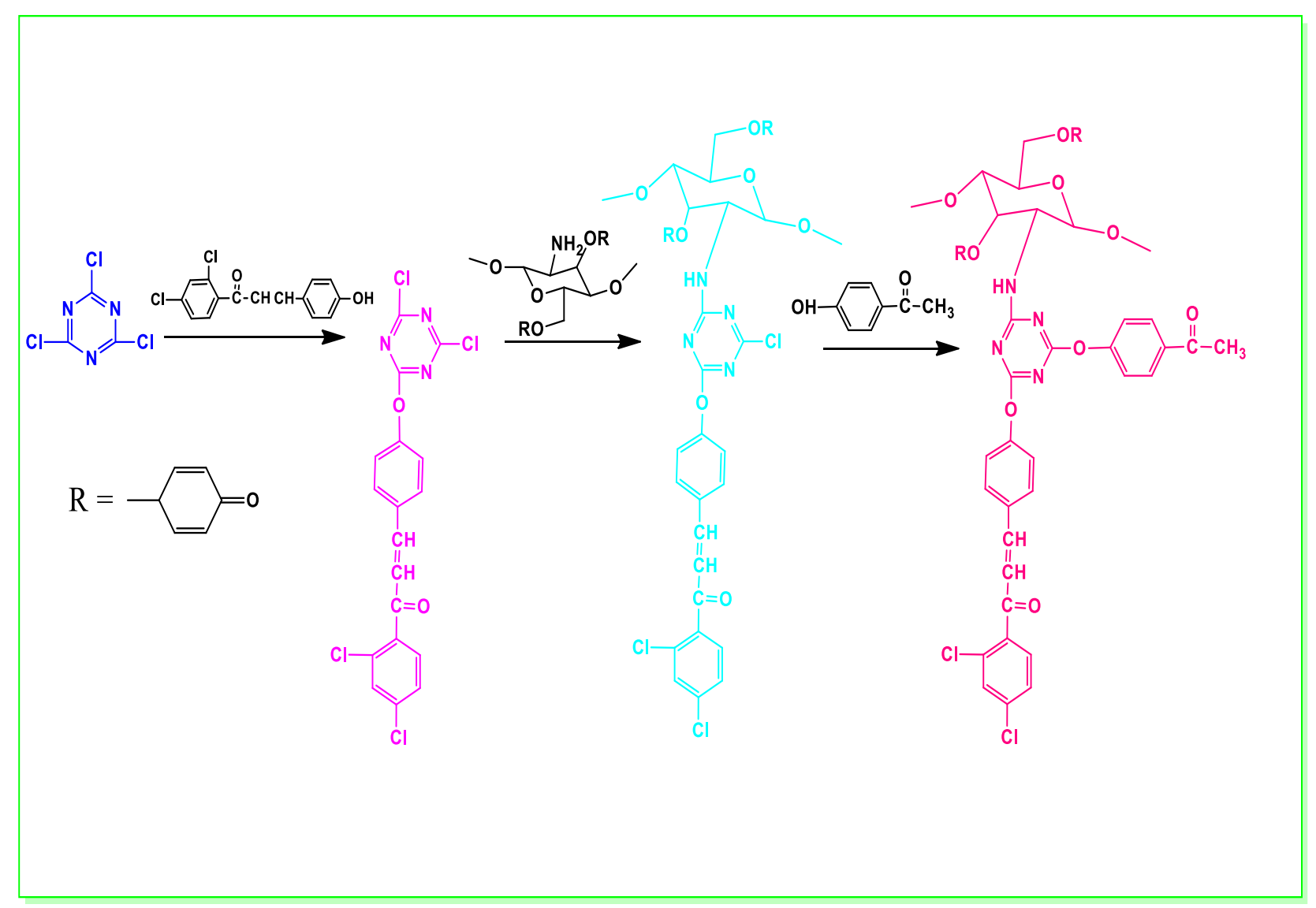

Scheme 2: Synthesis of chitosan based acetophenone

Cyanuric chloride dissolved in acetone and the DHP $(4.766 \mathrm{~g}, 0.01 \mathrm{~mol}$ in $30 \mathrm{~mL}$ acetone) with constant stirring for $3 \mathrm{hr}$ at $0-5^{0} \mathrm{C}$, periodically $10 \% \mathrm{Na}_{2} \mathrm{CO}_{3}$ solution was added drop wise. After completion of the reaction, the mixture (CYDHP) was poured into ice-cold water, the precipitate was separated out by filtration and washed several times by using cold water and dried in vacuum at $50^{\circ} \mathrm{C}$. Synthetic route is given in the scheme 2, IR $(\mathrm{KBr}, \mathrm{cm}-1): 3305(\mathrm{~N}-\mathrm{H}$ 
str.), 3070 (=CH str.), 1649 (C=O str.), 1510 (C=C str.), 1025 (C-O-C str.), 808 (C-N str., striazine moiety), $1080 \mathrm{~cm}-1$ (C-Cl str.) ; 1H NMR(CDCl3, $\delta, \mathrm{ppm}): 6.42(1 \mathrm{H}, \mathrm{d},-\mathrm{CO}-\mathrm{CH}=), 8.03$ $(1 \mathrm{H}, \mathrm{d}, \mathrm{Ar}-\mathrm{CH}=), 6.98-7.91(17 \mathrm{H}, m, \mathrm{Ar}-\mathrm{H}$ and $-\mathrm{NH})$.

\subsection{Synthesis of chitosan based cynuric chloride containing chalcone moiety (CCCM)} (Scheme 2)

Synthetic route of CCCM was presented in the scheme 2. Aminated chitosan (AMC) dissolved in the acetic acid were added to CYDHP $(5 \mathrm{~g}, 0.011 \mathrm{~mol})$ dissolved in acetone $(4.25 \mathrm{~g}$ in $50 \mathrm{~mL}$ acetic acid) with constant stirring for $3 \mathrm{hr}$ at room temperature and periodically $10 \%$ $\mathrm{Na}_{2} \mathrm{CO}_{3}$ solution was added drop wise to neutralize the solution. After completion of the reaction, the reaction mixture was poured into ice-cold water, the precipitate was separated out by filtration and washed several times using cold water and dried in vacuum at $50{ }^{0} \mathrm{C}$. Yield: 4.4 $\mathrm{g}(58 \%)$. The IR spectra $\left(\mathrm{cm}^{-1}\right)$ revels the peak at 3305 is due to the presence of N-H stretching, at 3070 is due to aromatic $\mathrm{CH}$ stretching, at 1663 is due to the presence of $\mathrm{C}=\mathrm{O}$ stretching, at 1603 and 1570 is due to $\mathrm{C}=\mathrm{C}$ and $\mathrm{Ar}-\mathrm{NO}_{2}$ stretching respectively. The peak at 1080 is due to the $\mathrm{C}-\mathrm{Cl}$ stretching, at 1025 is due to $\mathrm{C}-\mathrm{O}-\mathrm{C}$ stretching and at 812 is due to $\mathrm{C}-\mathrm{N}$ stretching of $s$ triazine moiety. further two characteristic peak of absorption, around $250 \mathrm{~nm}$ is due to aromatic double bond and the peak of absorption at $330 \mathrm{~nm}$ is due to $\pi$ to $\pi^{*}$ transition of $>\mathrm{CH}=\mathrm{CH}<$ in the NTP system. ${ }^{1} \mathrm{H}$ NMR $(\delta$, ppm), Characteristic chemical shifts present in the spectrum are, the peak at 7.3-8 is due to aromatic protons $(11 \mathrm{H})$, at 6.8-6.9 is due to the $-\mathrm{CO}-\mathrm{CH}=\mathrm{CH}$ proton and the peak at 4.1 is due to the presence of Ar-NH in the NTP system. 


\subsection{Synthesis of chitosan based acetophenone (CCA) (scheme 2)}

Synthetic route of CCA is presented in the scheme 2. In a RB flask containing $5.23 \mathrm{~g}$ of CCCM in acetic acid to this 4-hydroxyacetophenone $(0.68 \mathrm{~g}, 0.005 \mathrm{~mol})$ dissolved in acetone was added slowly to it with constant stirring for $6 \mathrm{~h}$ at $70^{\circ} \mathrm{C}$. Periodically, $10 \% \mathrm{Na}_{2} \mathrm{CO}_{3}$ solution is added to neutralize the $\mathrm{HCl}$ evolved during the reaction. Finally, the contents were poured into a crushed ice, the solid separated out and filtered and washed with water, dried and recrystalized form ethyl alcohol. Yield: $2.5 \mathrm{~g}(79 \%)$ and the m.p is $172-174{ }^{\circ} \mathrm{C}$. FT-IR $\left(\mathrm{cm}^{-1}\right)$, the peak appear at $3305\left(\mathrm{~cm}^{-1}\right)$, is due to the $\mathrm{N}-\mathrm{H}$ stretching, at $3070\left(\mathrm{~cm}^{-1}\right)$, is due to aromatic $\mathrm{CH}$ stretching, at $1675\left(\mathrm{~cm}^{-1}\right)$, is due to the presence of free and conjugated $\mathrm{C}=\mathrm{O}$ stretching, at $1593\left(\mathrm{~cm}^{-1}\right)$, is due $\mathrm{C}=\mathrm{C}$ stretching, at $1028\left(\mathrm{~cm}^{-1}\right)$, is due to the $\mathrm{C}-\mathrm{O}-\mathrm{C}$ stretching, at $1565\left(\mathrm{~cm}^{-1}\right)$, is due to $\mathrm{Ar}-\mathrm{NO}_{2}$ stretching, at $1083\left(\mathrm{~cm}^{-1}\right)$, is due to $\mathrm{C}-\mathrm{Cl}$ stretching and $810\left(\mathrm{~cm}^{-1}\right)$, is due to the $\mathrm{C}-\mathrm{N}$ stretching of parental s-triazine moiety. UV $(\mathrm{nm})$ spectrum reveals the two characteristic peak of absorption at $254 \mathrm{~nm}$ is due to aromatic double bond absorption and the peak of absorption at $336 \mathrm{~nm}$ is due to $\pi$ to $\pi^{*}$ transition of $>\mathrm{CH}=\mathrm{CH}<$ in the CCA system. ${ }^{1} \mathrm{H}$ NMR $(\delta, p p m)$, characteristic chemical shifts present in the spectrum are, the peak at 6.8 to 8.1 is due to vinylic $(2 \mathrm{H})$ and aromatic protons $(15 \mathrm{H})$ and the peak at 4.1 is due to Ar-NH proton. The peak appear at 3.86 is due to the presence of $-\mathrm{CO}-\mathrm{CH}_{3}$ in the $\mathrm{CCA}$ system.

\subsection{Synthesis of triazine containing novel chalcones (scheme 3) Grindstone technique}

Newly synthesized chalcones were prepared by grinding together equivalent amount of CCA and substituted benzaldehydes in presence of $\mathrm{KOH}$ in a porcelain mortar under solvent free conditions for 4-8mins. On completion of reaction, the mixture was diluted with cold water neutralized by dilute $\mathrm{HCl}$ and recrystallized from acetic acid. . 


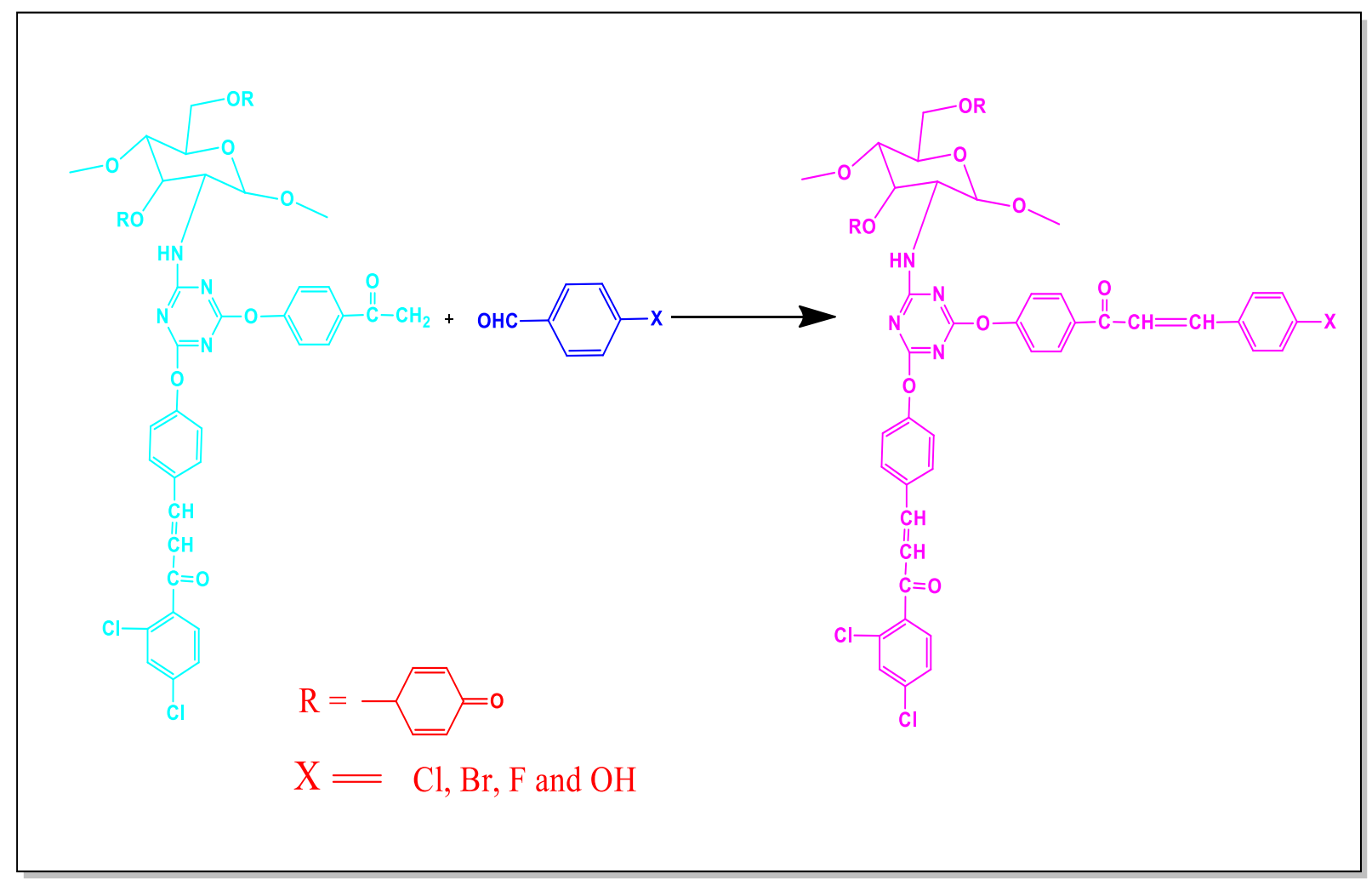

Scheme 2: Synthesis of Chalcones CCBC, CCCC, CCFC and CCHC.

\section{Results and Discussions.}

\subsection{UV, FT-IR and Proton NMR analysis}

All the synthesized chalcones has been characterized using FT-IR, proton NMR and UVvisible spectroscopic techniques and the data obtained are illustrated as below. UV-visible (nm): The obtained UV-visible spectrum shows two predominant peak at around 230 and 330 is due to $\pi-\pi^{*}$ transition of aromatic $\mathrm{CH}=\mathrm{CH}$ and vinylic $\mathrm{CH}=\mathrm{CH}$ respectively. The FT-IR spectrum has been taken for the hybrid chitosan derivatives and their intermediates in order to confirm the formation. The peak appeared at $1583 \mathrm{~cm}^{-1}$ is due the $\mathrm{C}=\mathrm{C}$, and at $1664 \mathrm{~cm}^{-1}$ is due to the $\mathrm{CO}$ of the newly formed chalcone. The presence of secondary NH groups appear at $3013 \mathrm{~cm}^{-1}$ and the presence of azo $(-\mathrm{N}=\mathrm{N}-)$ group appeared at $1579 \mathrm{~cm}^{-1} .{ }^{1} \mathrm{H}-\mathrm{NMR}(\delta, \mathrm{ppm})$, the presence of vinylic 
proton appeared at 5-5.2. The cluster of peak appeared at 4-5.1 is corresponds to the protons of the chitosan and the presence of 15 aromatic protons appeared at 6.5-8 as a muliplets.

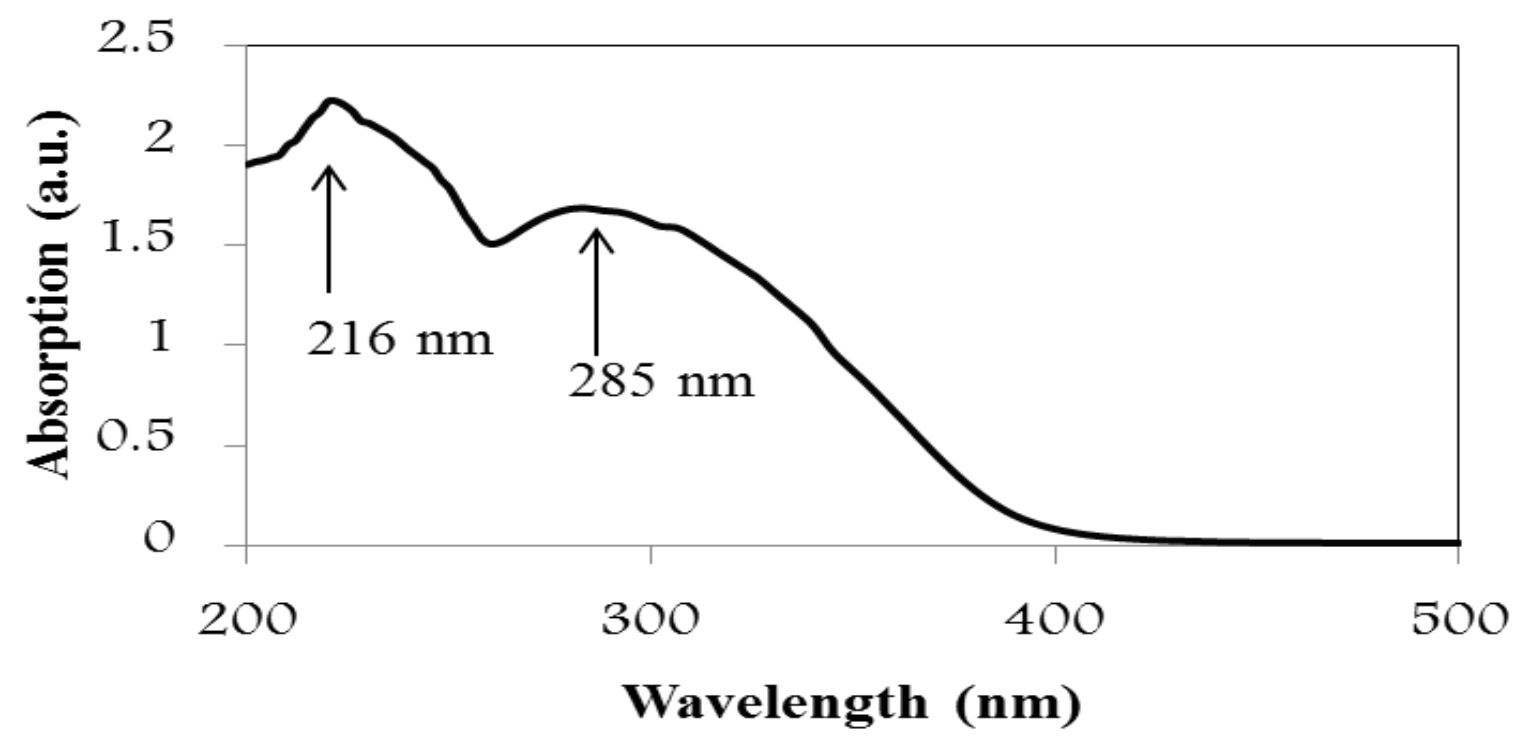

Figure 1: UV Spectrum of CCCC

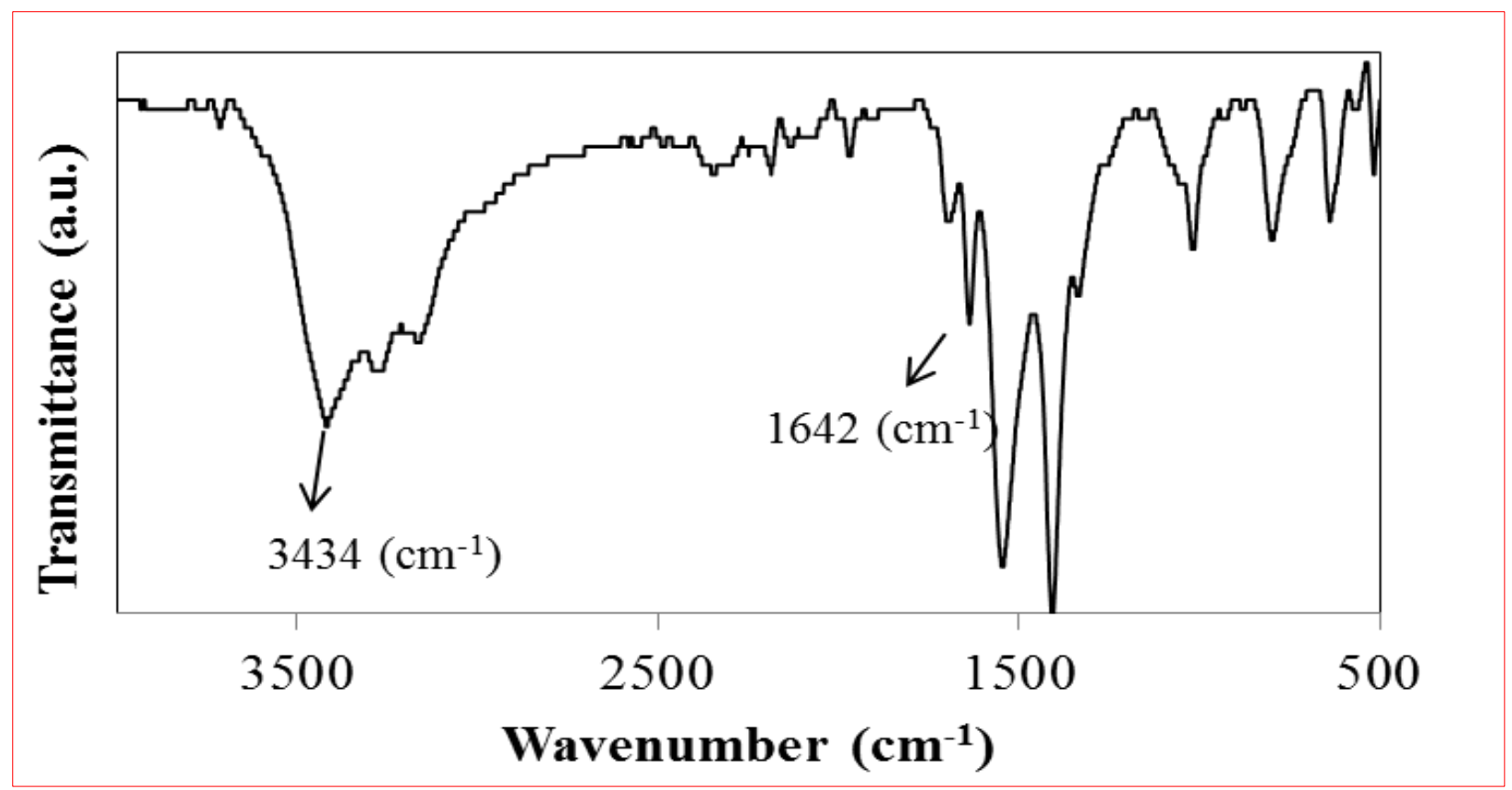




\section{Figure 2: FT-IR Spectrum of CCCC}

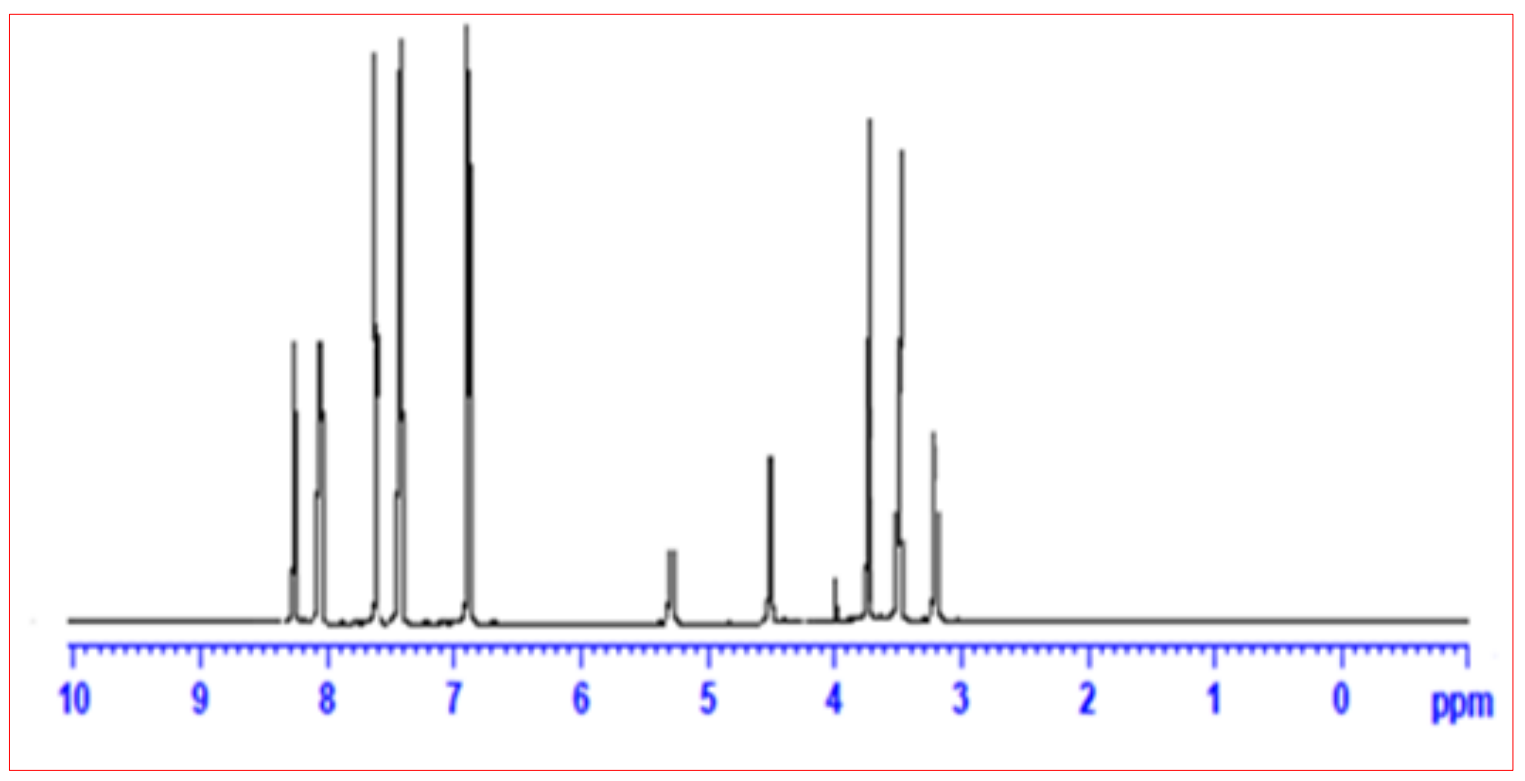

Figure 3: ${ }^{1} \mathrm{H}-\mathrm{NMR}$ Spectrum of CCCC Thermal response -TGA analysis

Thermo gravimetric analysis is used to find out the thermal stability of the synthesized materials. Pure chitosan shows single stage decomposition around at $276^{\circ} \mathrm{C}$ whereas the synthesized chitosan derivatives show single stage decomposition. It clearly suggests that the synthesized compound shows higher thermal stability than the parental chitosan. This compound shows excellent thermal stability on heating, chitosan based compound always shows two stage decomposition on heating Figure 4 is the TGA spectrum of CCCC, shows two stage decompositions, first decomposition temperature centered at $276^{\circ} \mathrm{C}$ and second decomposition temperature centered at $566^{\circ} \mathrm{C}$. First decomposition is due to removal cyanuric chloride derivatives, which is present in chitosan as a side chain. Second decomposition is due to complete decomposition of chitosan main chain. All the synthesized composites of chitosan with cynuric chloride derivatives also showed the double stage decomposition and the data's were is 
presented in the table 1 . The obtained two stage decomposition of the synthesized composites is in good agreement with previously reported values (11)

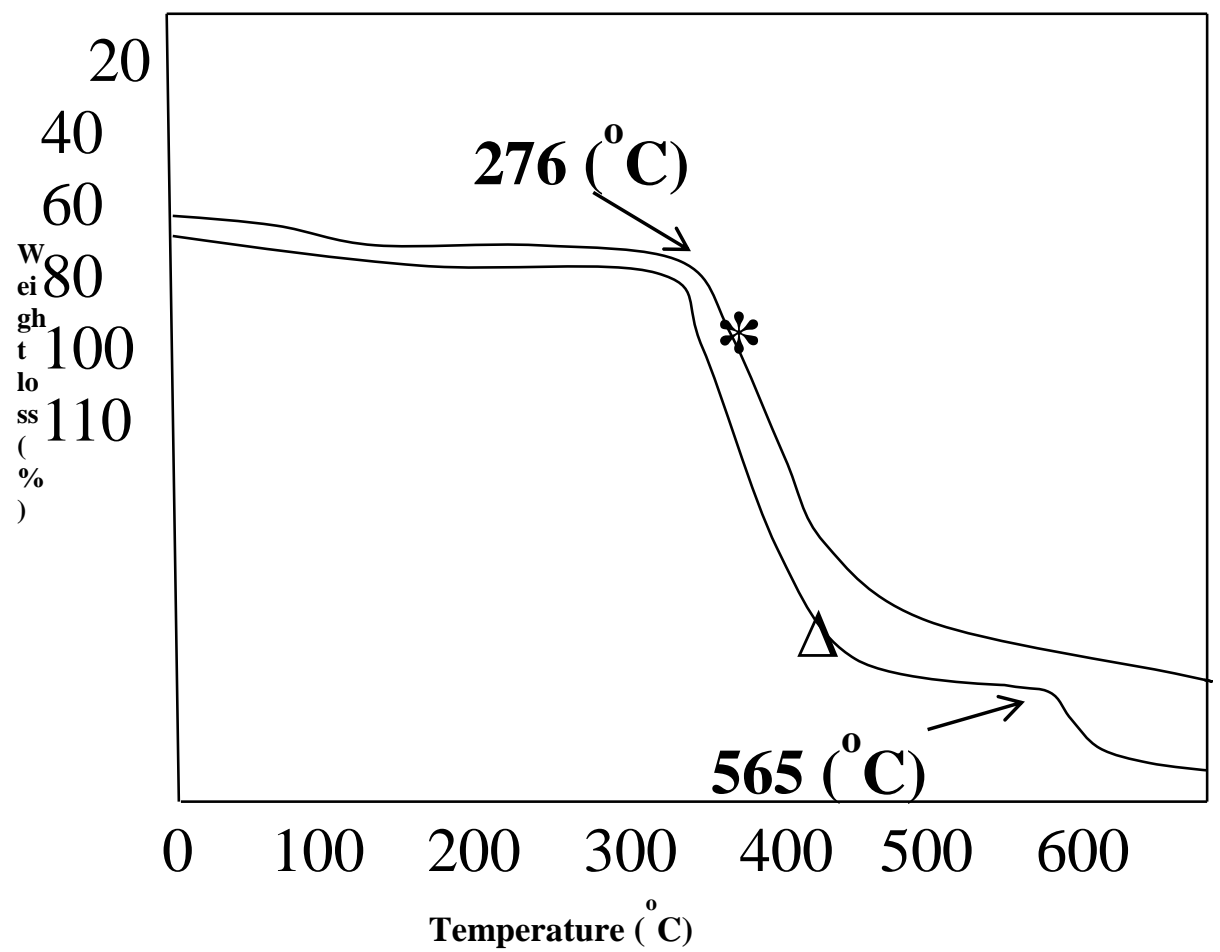

Figure 4: TGA Spectrum * $=$ Pure Chitosan and $\Delta=$ CCC

Table 1: TGA data's of the synthesized composites CCCC, CCBC, CCFC and CCHC.

\begin{tabular}{ccc}
\hline Synthesized composites & \multicolumn{2}{c}{ Decomposition temperature ${ }^{0} \mathrm{C}$} \\
\cline { 2 - 3 } & First decomposition & Second decomposition \\
\hline Pure Chitosan & 276 & ---- \\
CCCC & 276 & 565 \\
CCBC & 277 & 570 \\
CCFC & 270 & 560 \\
CCHC & 268 & 554 \\
\hline
\end{tabular}




\subsection{ANTIBACTERIAL ACTIVITY}

Bacteria used for the determination of antibacterial activities of compounds were Gram positive; Staphylococcus aureus MTCC 29213, Gram negative; Pseudomonas aeruginosa MTCC 2488. All bacterial strains were obtained from Microbial Type Culture Collection and Gene Bank, Institute of Microbial Technology Sector 39-A, Chandigarh-160036, India. All bacterial strains were sub cultured on nutrient agar medium, incubated at $37^{\circ} \mathrm{C}$ for 24 hrs and stored at $4^{\circ} \mathrm{C}$ in refrigerator to maintain stock culture $(5,6)$.

\subsubsection{MEDIA USED}

\begin{tabular}{|c|c|c|c|c|c|}
\hline Materials & Nutrient & Nutrient & Materials & Muller & Muller \\
\hline & $\begin{array}{l}\text { Agar(NA) } \\
\text { (g/litre) }\end{array}$ & broth (NB) & & $\begin{array}{l}\text { Hilton agar } \\
\text { (gram/litre) }\end{array}$ & $\begin{array}{l}\text { Hilton broth } \\
\text { (gram/litre) }\end{array}$ \\
\hline Peptone & 5 & 5 & $\begin{array}{l}\text { Beef Extract } \\
\text { Powder }\end{array}$ & 2.0 & 2.0 \\
\hline Yeast extract & 2 & 2 & $\begin{array}{l}\text { Acid Digest } \\
\text { of Casein }\end{array}$ & 17.5 & 17.5 \\
\hline $\mathrm{NaCl}$ & 5 & 5 & Starch & 1.5 & 1.5 \\
\hline Agar & 18 & -- & Agar & 17 & --- \\
\hline $\begin{array}{l}\text { Distilled } \\
\text { water }\end{array}$ & 1000 & 1000 & $\mathrm{PH}$ & 7 & 7 \\
\hline $\mathrm{pH}$ & 7 & 7 & -- & -- & -- \\
\hline
\end{tabular}

\subsubsection{MINIMUM INHIBITORY CONCENTRATIONS (MICS)}

The minimum inhibitory concentrations of the synthesized compounds $C C B C, C C C C$, CCFC and CCHC were determined by dilution method (Brantner and Grein, 1994). The strains were grown in Mueller Hinton broth to exponential phase with an A560 of 0.8, representing $3 \times 10^{8} \mathrm{CFU} / \mathrm{ml}$. Different concentration $(7.8,15.6,31.2,62.5,125 \mathrm{and} 250 \mu \mathrm{g} / \mathrm{ml})$ of synthesized 
compounds (1mg of compound in $1 \mathrm{ml}$ of $7 \%$ DMSO) were added on to separate test tubes containing $4 \mathrm{ml}$ of $\mathrm{MH}$ broth inoculated with $0.5 \mathrm{ml}$ bacterial suspension at a final concentration of $10^{8} \mathrm{CFU} / \mathrm{ml}$. Each MIC was determined from five independent experiments performed in triplicates. The tubes containing $4.5 \mathrm{ml}$ of bacterial inoculates and $0.5 \mathrm{ml}$ of $7 \%$ DMSO were used as bacterial control, $4.5 \mathrm{ml}$ of uninoculated Mueller Hinton broth and $0.5 \mathrm{ml} 7 \%$ DMSO served as a blank. The tubes were incubated at $37^{\circ} \mathrm{C}$ for $18 \mathrm{~h}$; inhibition of bacterial growth was determined by measuring the absorbance at $A 560 \mathrm{~nm}$. MICs results revealed that the OD value was higher in the control because the bacteria caused turbidity. There was a gradual decrease in the optical density at higher dilution, whereas the compound CCC showed more inhibitory activity at the lowest dilutions (MIC $7.8 \mu \mathrm{g} / \mathrm{ml}$ ) than other compounds (MIC $7.8 \mu \mathrm{g} / \mathrm{ml}$ ) against Gram-negative pathogens such as Pseudomonas aeruginosa; and Gram-positive bacteria such as Staphylococcus aureus (Figure 4). $7.8 \mu \mathrm{g} / \mathrm{ml}$ was the effective (MIC) concentration for the inhibitory effect of all compounds tested against bacteria. The antimicrobial activity of compound P-30 was weaker against both microorganisms.

\subsubsection{Antimicrobial Activity-Results and Discussion Sample Preparation:}

$20 \mathrm{mg}$ of given sample was dissolved in $100 \mu \mathrm{l}$ of DMSO and $900 \mu \mathrm{l}$ of distilled water (CCBC, CCCC, $\mathrm{CCFC}, \mathrm{CCHC})$.

\section{Minimum Inhibitory concentration (MIC)}

The samples were subjected to antibacterial activity by micro dilution method against Pseudomonas aeruginosa and Staphylococcus aureus. Luria broth (Himedia, Mumbai) was prepared and sterilized by autoclaving at $121^{\circ} \mathrm{C}, 15 \mathrm{lbs}$, for 15 minutes. $100 \mu \mathrm{l}$ of broth was added to the 96 well micro titre plates. The $100 \mu \mathrm{l}$ of the given sample was added in the first well and then serially diluted till the eighth well. The $10 \mu \mathrm{l}$ of $\log$ phase culture was introduced into 
the respective wells. Similarly tetracycline $(100 \mu 1$ from $10 \mathrm{mg} / \mathrm{ml})$ was added to $100 \mu$ of broth and serially diluted. Then $10 \mu \mathrm{l}$ of $\log$ phase culture was added. This served as the positive control. Broth and culture was taken as Negative control. Sterile broth serves as a control. The plates were incubated at $37^{\circ} \mathrm{C}$ for $24 \mathrm{~h}$. MIC was determined as the complete growth inhibition at the lowest concentration of the sample.
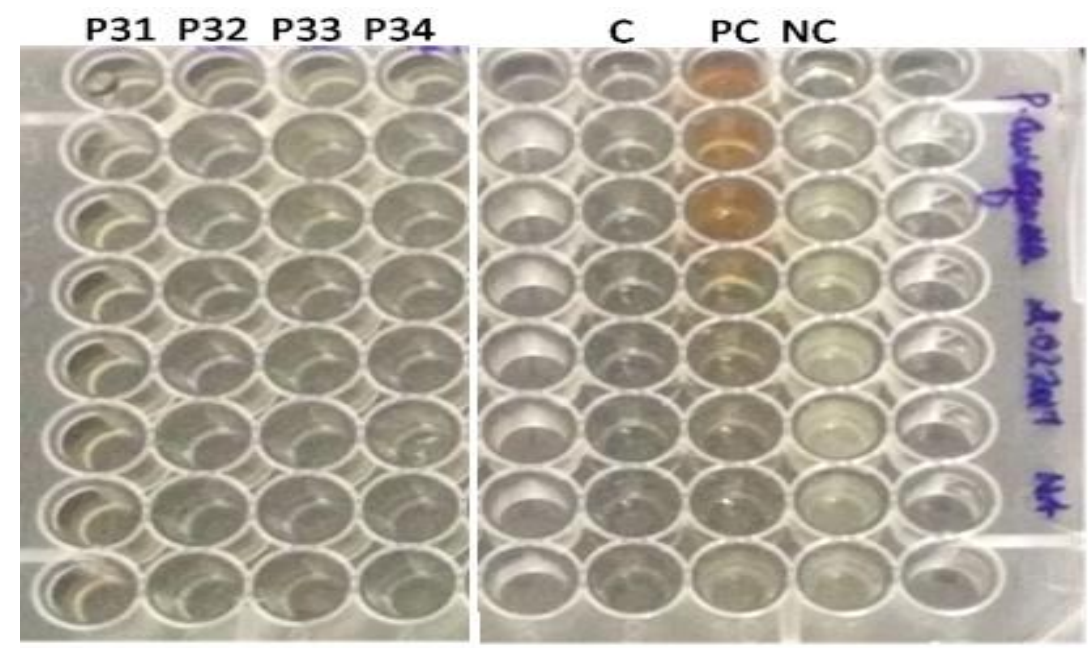

Figure:5 shows antibacterial activity of Samples against Pseudomonas aeruginosa by using broth micro dilution method, tetracycline was used as a Positive control (12), Negative control - Broth and Culture (11), Control - Broth(10).

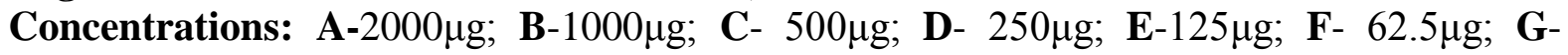
$31.25 \mu \mathrm{g} ; \mathbf{H}-15.62 \mu \mathrm{g}$

Table: 2 Antibacterial activity of samples against Pseudomonas aeruginosa

\begin{tabular}{ccc}
\hline Name of the sample & $\begin{array}{c}\text { Antibacterial Activity } \\
\text { Minimum Inhibitory } \\
\text { Concentration }(\boldsymbol{\mu g})\end{array}$ & Tetracycline $(\boldsymbol{\mu g})$ \\
\hline CCBC & 15.63 & 7.81 \\
CCCC & 15.63 & 7.81 \\
CCFE & 15.63 & 7.81 \\
CCHC & 31.25 & 7.81 \\
\hline
\end{tabular}




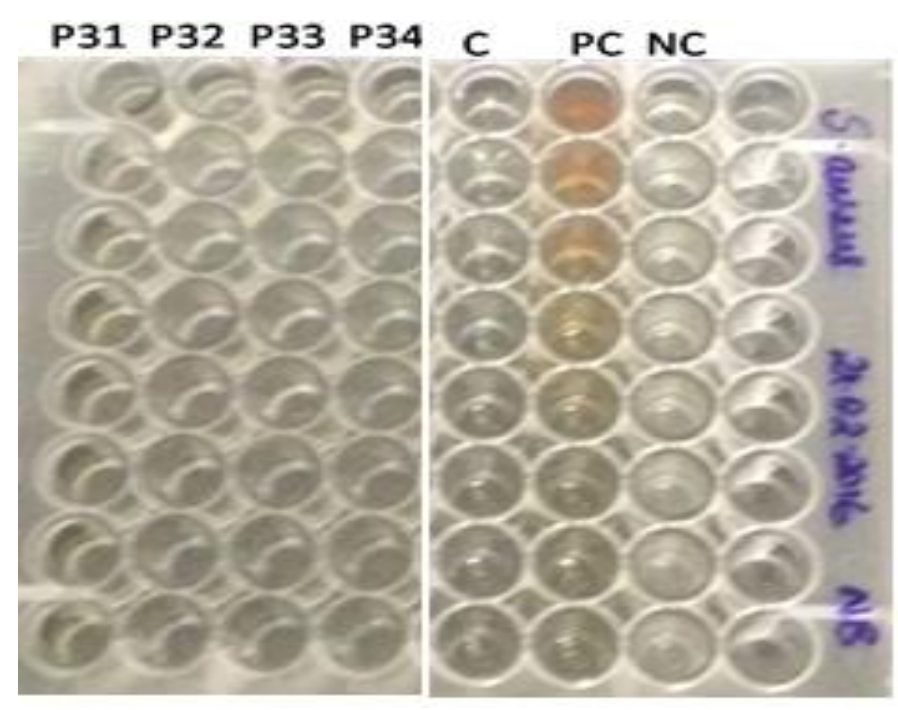

Figure:6 shows antibacterial activity of Samples (P51 to PSTM) against Staphylocoocus aureus respectively by using broth micro dilution method, tetracycline was used as a Positive control (12), Negative control - Broth and Culture (11), Control - Broth(10).

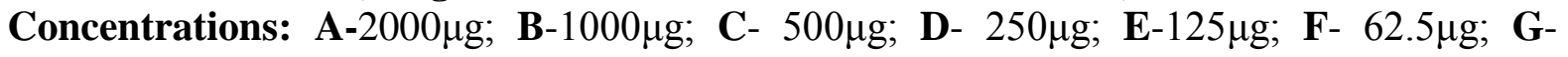
$31.25 \mu \mathrm{g} ; \mathbf{H}-15.25 \mu \mathrm{g}$

Table: 3 Antibacterial activity of samples against Staphylocoocus aureus

\begin{tabular}{ccc}
\hline Name of the sample & $\begin{array}{c}\text { Antibacterial Activity } \\
\text { Minimum Inhibitory } \\
\text { Concentration }(\boldsymbol{\mu g})\end{array}$ & Tetracycline $(\boldsymbol{\mu g})$ \\
\hline CCBC & 31.25 & 7.81 \\
CCCC & 15.63 & 7.81 \\
CCFE & 15.63 & 7.81 \\
CCHC & 31.25 & 7.81 \\
\hline
\end{tabular}

\section{MTT assay for Cytotoxicity}

The MTT assay (Mossman, 1983) is based on the ability of live but not dead cells to reduce a yellow tetrazolium dye to a purple formazan product. Cells were maintained in DMEM medium, supplemented with $10 \%$ Fetal Bovine Serum, at $37^{\circ} \mathrm{C}$ in humidified atmosphere with 
$5 \% \mathrm{CO}_{2}$. The COLO320 cells were plated in 96 well flat bottom tissue culture plates at a density of approximately $1.2 \times 10^{4}$ cells/well and allowed to attach overnight at $37^{\circ} \mathrm{C}$. The medium was then discarded and cells were incubated with different concentrations of the samples $(25,50$, $75,100 \& 125 \mu \mathrm{g})$ for 24 hours. After the incubation, medium was discarded and $100 \mu 1$ fresh medium was added with $10 \mu \mathrm{l}$ of MTT $(5 \mathrm{mg} / \mathrm{ml})$. After 4 hours, the medium was discarded and $100 \mu \mathrm{l}$ of DMSO was added to dissolve the formazan crystals. Then, the absorbance was read at 570nm in a microtitre plate reader. Cyclophosphamide was used as a positive control. Medium along with cells (untreated) serves as a control.

Cell survival was calculated by the following formula:

Viability $\%=($ Test OD/ Control OD) X 100

Cytotoxicity $\%=100-$ Viability $\%$

Table 4: shows the \% Cytotoxicity of sample CCHC

\begin{tabular}{ccc}
\hline Concentration $(\boldsymbol{\mu g})$ & CCCC & Positive Control \\
\hline 25 & 18.69 & 76.65 \\
50 & 22.97 & 81.52 \\
75 & 28.63 & 83.08 \\
100 & 33.71 & 85.16 \\
125 & 35.86 & 89.59 \\
\hline
\end{tabular}

\begin{tabular}{ccc}
\hline Concentration $(\boldsymbol{\mu g})$ & CCFC & Positive Control \\
\hline 25 & 18.48 & 76.35 \\
50 & 21.97 & 79.42 \\
75 & 27.53 & 82.78 \\
100 & 33.01 & 83.36 \\
125 & 34.86 & 88.39 \\
\hline
\end{tabular}




\begin{tabular}{ccc}
\hline Concentration $(\boldsymbol{\mu g})$ & CCBC & Positive Control \\
\hline 25 & 17.18 & 76.55 \\
50 & 20.37 & 79.32 \\
75 & 26.63 & 81.28 \\
100 & 31.31 & 83.06 \\
125 & 33.56 & 88.69 \\
\hline
\end{tabular}

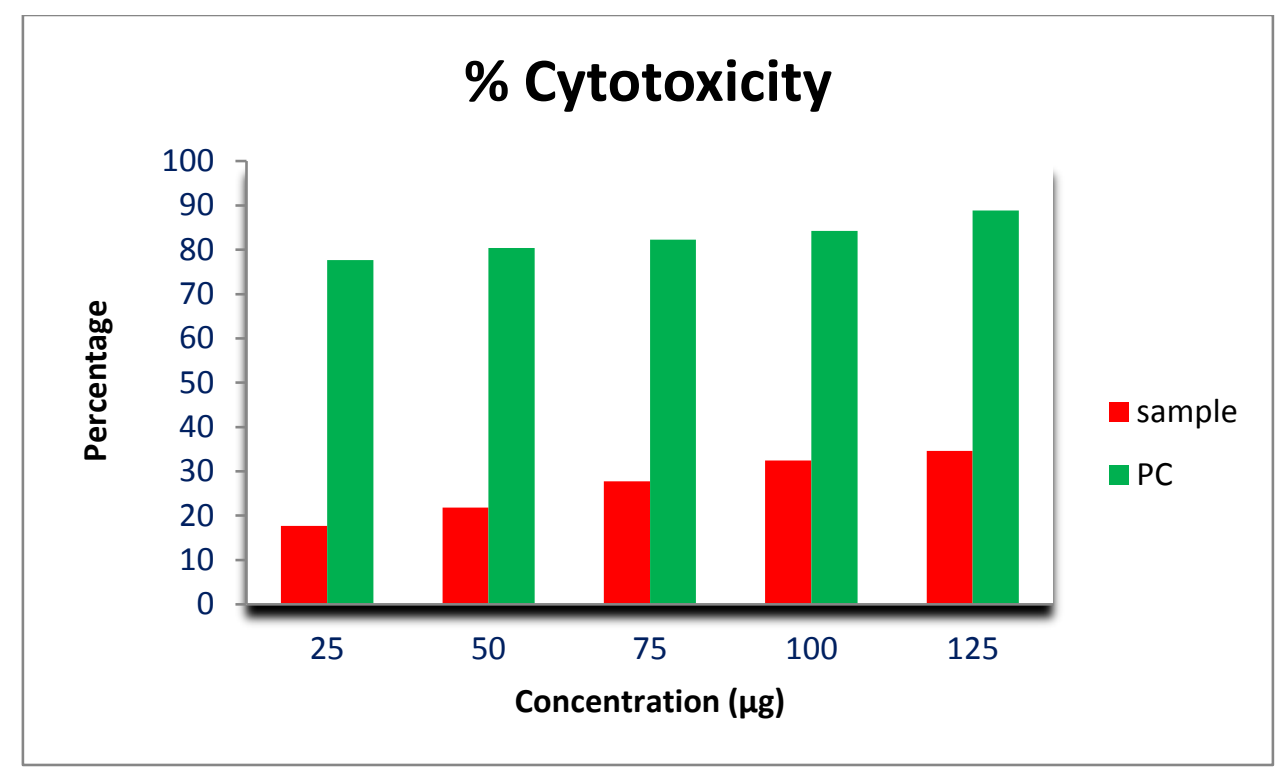

Figure:6 shows the \% Cytotoxicity CCCC Cytotoxicity activity of the $\mathrm{CCCC}, \mathrm{CCBC}, \mathrm{CCFC}$ and $\mathrm{CCHC}$.

Synthesized composites were screened for their cytotoxicity activity on COLO320 cells and the obtained data's were presented in the table 4 . From the table it is clear that the synthesized composite shows good activity against COLO320. The composites CCCC, CCBC, CCFC and CCHC are prepared using chitosan and triazine derivatives containg chalcone unit. The presence of chitosan, cynanuric chloride and chalcone in the composite is responsible for the higher cytotoxicity activity. Several researchers already found higher cytotoxicity activity of chitosan derivatives (12-14) as well as triazine derivatives (14-16). The presence of chalcone 
molecule with chitosan and cynuric chloride is enhancing the cytotoxicity activity of the synthesized composites. The concentration of the synthesized composite increase, the positive controls also increase irrespective of the nature of the composite. CCCC shows little high activity than the $\mathrm{CCBC}, \mathrm{CCFC}$ and $\mathrm{CCHC}$ the presence of chlorine in $\mathrm{CCCC}$ is responsible for the little high activity than others. The presence of hydroxyl group in CCHC also shows excellent cytotoxicity activity as like halogen containing synthesized composite. The positive control value obtained high for the highest concentration of the composite, around 88 has been obtained for $125(\mu \mathrm{g})$ of the composite concentration.

\subsection{Solubility of the synthesized compounds}

The water sorption of the chitosan was attributed to the hydrophilic groups of the polysaccharide chains (hydroxyl and amino groups). From the table (5), it was clear that increase of the water sorption of aminated chitosan over the chitosan itself. This was explained by increase the hydrophilic groups on the chitosanvia grafted with amine groups. In the other hand, the increase

Table : 5 Solubility Data of the novel chalcones at $30^{\circ} \mathrm{C}$

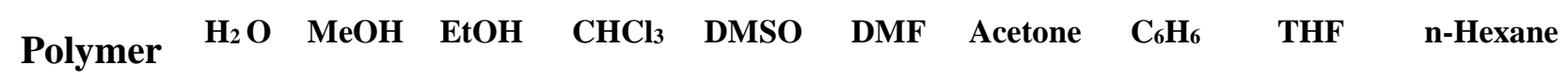

\begin{tabular}{cccccccccccc}
\hline $\mathrm{CCBC}$ & - & + & + & + & + & + & + & + & + & - \\
$\mathrm{CCCC}$ & - & + & + & + & + & + & + & - & + & - \\
$\mathrm{CCFC}$ & - & \pm & \pm & \pm & + & \pm & \pm & - & \pm & - \\
$\mathrm{CCHC}$ & - & + & \pm & \pm & + & + & + & - & + & - \\
\hline \multicolumn{7}{c}{} \\
\hline
\end{tabular}


of the water sorption of the aminated chitosan as increase the plasticizer percent was attributed to the hydrophilic power of the glycerol as polyols and also results from the effect of the plasticizer on the limitation of crystal linty of the membrane. The solubility data of the synthesized compounds are presented in the table 5. The $C C B C, C C C C, C C F C$ and $C C H C$ are almost soluble in all the solvents used for solubility test except water, benzene and n-hexane but freely soluble in methanol, ethanol, dimethylsulfoxide, dimethylformamide and tetrahydrofuran.

\section{CONCLUSION}

There are four novel hybrid chitosan and chalcones were synthesized using novely prepared and tested for its biological activity. All the synthesized compounds were characterized by FTIR, NMR and UV spectroscopy techniques. All the synthesized chalcones were completely soluble in polar protic solvents like acetone, alcohol, DMSO, THF, ether but insoluble in water. Melting points of all the synthesized compounds were determined in an open capillary and found to be dependent on the molecular weight of the compounds. Antimicrobial activity of $C C B C$, CCCC, CCFC and CCHC were tested on Staphylococcus aureus and Pseudomonas aeruginosa. CFHC showed more inhibitory activity at the lowest dilutions (MIC 7.8 $\mu \mathrm{g} / \mathrm{ml}$ ) than other compounds (MIC $7.8 \mu \mathrm{g} / \mathrm{ml}$ ) against Gram-negative pathogens such as Pseudomonas aeruginosa. Whereas CCC showed excellent activity on tested gram positive Staphylococcus aureus bacteria's with the MIC value of $15.63 \mu \mathrm{g} / \mathrm{ml}$. Which clearly shows that there is no vital change in the antimicrobial activity of synthesized chalcone containing halogen moiety but this activity is high when compare with chalcone containing hydroxyl. This is due to the availability of electron in the halogen moiety than other chalcone. Chitosan beinga biocompatible material its hybrid chalcones possess superior antibacterial and anticancer properties. The synthesize hybrid 
polymer possess great scope for cancer treatments, wound dressing and drug delivery other pharmocogical applications in the future

\section{REFERENCES}

1. Aider, M. (2010). Chitosan application for active bio-based films production and potential in the food industry: review. LWT e Food Science and Technology, 43, 837e842.

2. C.E.P. Bonilla, S. Trujillo, B. Demirdogen, J.E. Perilla, Y.M. Elçin, J.L.G. Ribelles, (2014) New porous polycaprolactone-silica composites for bone regeneration, Mater. Sci. Eng., C: Biomimetic Supramol. Syst. 40,418-426.

3. Anna R., Małgorzata K.-L.,Victor S., Silvia I., Manuel A., \& Gra`z. S. 2017 : RSC Adv., 75.

4. Boddu, V. M., Smith, E. D., \& Nano, G. (2001). Bridges, 10, 418.

5. Boddu, V.M., Abburi, K., Talbott, J. L., Smith, E. D., \& Haasch, R. (2008). Water Research, 42, 633e642.

6. Dambies, L., Vincent, T., \& Guibal, E. (2002). Water Research, 36, 3699e3710.

7. De Alvarenga, E. S. (2011). Biotechnology of Biopolymers, 91.

8. Gupta, A., Chauhan, V. S., \& Sankararamakrishnan, N. (2009).. Water Research, 43, 38623870.

9. Lifeng Q., Zirong X., Xia J., Caihong H., \& Xiangfei Z.(2004) Carbohydrate Research $3392693-2700$.

10. Mossman T. (1983) J.Immunol.Methods. 65 55-63.

11. Ponnurangam M. S.,Veluchamy P., Ramalingam N., \& Mukesh D. (2014). Biomater Sci 2, 990.

12. Shi, H., Shi, X., \& Liu, K. J. (2004). Molecular and Cellular Biochemistry, 255, 67e78. 
13. Smidsrod, O. (1990). Trends in Biotechnology, 8, 71-78.

14. Soner Altundo_gan, H., Altundo_gan, S., Tu“ men, F., \& Bildik, M.(2000). Waste Management, 20, 761e767.

15. Sonja, F., Carola S., Ulrich B., \& Kristina J. S. (2005). Journal of Antimicrobial Chemotherapy, 55, 883-887.

16. Xiao-J H., An-Guo Y., Zhi-K,. X. (2008) Bioresource Technology99 5459-5465. 